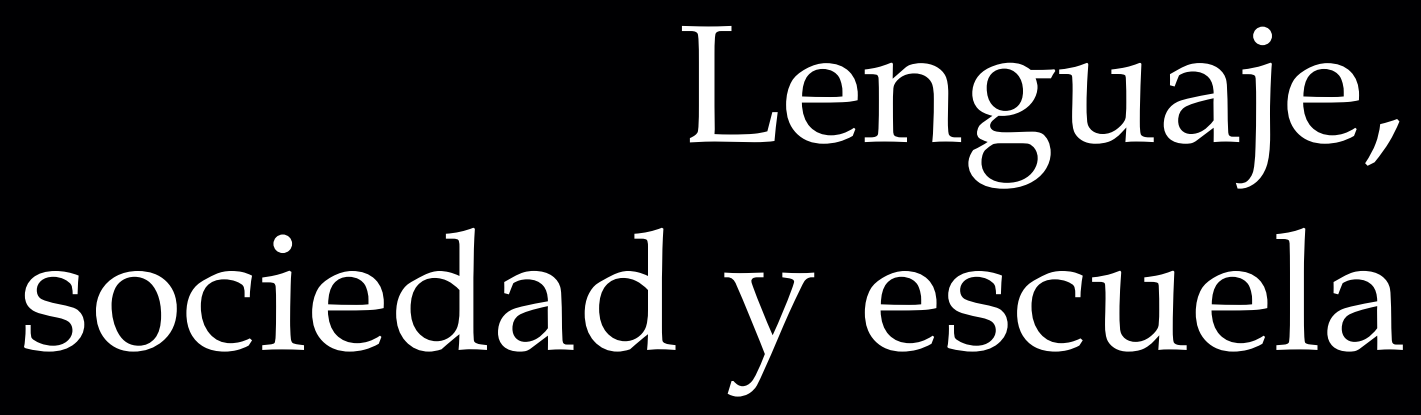




\title{
Enunciación
}

\section{Hermenéutica y metadidáctica en la comunicación literaria infantil: entre la sociodidáctica y el docente como mediador}

\author{
Hermeneutics and Metadidactics in Children's Literary Communication: Between \\ Sociodidactic and the Teacher as a Mediator
}

\author{
Susana Gómez Redondo*, Juan R. Coca*
}

\section{Resumen}

En este artículo abordamos, desde un enfoque metadidáctico y hermenéutico analógico, la literatura infantil (LI) en relación con la sociodidáctica y su tratamiento en las facultades de Educación. Con este fin, analizamos la metadidáctica y la LI, esta última en su doble condición de objeto literario y educativo. Esto nos lleva a revisar el viejo debate entre didactismo y literariedad. La investigación, basada en perspectivas transdiscisplinares y complejas, atiende al pensamiento del profesor como mediador entre la comunicación literaria infantil y el niño. Partimos de entender la LI como literatura de pleno derecho. No obstante, consideramos que su función socializadora e introductora al imaginario, unida a su pasado didáctico-moralizante, es en gran medida responsable de la instrumentalización que aún se observa en muchas aulas. Como profesores en una Facultad de Educación, percibimos también en nuestros estudiantes la anteposición del funcionalismo curricular sobre lo literario. Por ello, entendemos pertinente una interpretación metateórica, que aúne literatura, sociodidáctica y metadidáctica. Fundamentamos la reflexión en la hermenéutica analógica y la metadidáctica como epistemologías de primer y segundo orden. Nuestro objetivo es comprender mejor 1) la comunicación literaria infantil como objeto complejo; 2) su estatuto sociocultural y didáctico; 3) la percepción del docente en el proceso sociodidáctico de intermediación entre la LI y el niño; 4) el pensamiento de los futuros docentes sobre lo anterior, y 5) el aula como texto e interacción docente/discente a interpretar.

Palabras clave: literatura infantil, metadidáctica, hermenéutica analógica, universidad, docente, mediador.

\begin{abstract}
In this article, we discuss, from a meta-didactic and analogic hermeneutic approach, children's literature (CL) in relation to the sociodidactics and its status in faculties of Education. To this aim, we analyze meta-didactics and CL, the latter in its dual condition of a literary and educational object. This approach leads us to review the old debate between didacticismand literacy. Based on transdisciplinary and complex perspectives, the research focuses on the teacher's thoughts, like the mediator between childrens' literary communication and the child. We start by understanding children's literature like full-fledged literature. However, we consider that its' socializing and introductory to the imaginary function, together with its didactic-moralizing past, its' responsible in a good measure for instrumentalization that we can still observe in many classrooms. As teachers in a faculty of education, we also perceive in our students the predisposition of the curricular functionalism over literary. Therefore, we consider pertinent a metatheoretical interpretation that combines literature, socio-didactics and meta-didactics. We base the refection on analogic hermeneutic and meta-didactics as the first and second order of epistemology. Our purpose is to better understand 1) children's literary communication as a complex object; 2) its socio-cultural and didactic status; 3) the perception of the teacher in the socio-didactic process of intermediation between $\mathrm{CL}$ and the child; 4) the beliefs of future teachers about the above and 5) the classroom as text and teacher-learner interaction to interpret.
\end{abstract}

Keywords: childrens' literature; metadidactics; analogic hermeneutics; university; teacher; mediator.

* Licenciada en Ciencias de la Información y en Teoría de la Literatura y Literatura Comparada. Estudiante del Doctorado en Formación en la Sociedad del Conocimiento de la Universidad de Salamanca. En la actualidad imparte clases de Didáctica de la Lengua Castellana en la Universidad de Valladolid, Campus Soria. Correo electrónico:susana.gomezr@uva.es

** PhD en Sociología por la Universidad de Santiago de Compostela. Profesor del Departamento de Sociología y Trabajo Social de la Universidad de Valladolid. Correo electrónico: juancoca@soc.uva.es

Cómo citar este artículo: Gómez Redondo, S. y Coca, J. R. Hermenéutica y metadidáctica en la comunicación literaria infantil: entre la sociodidáctica y el docente como mediador. Enunciación, 22(1), 14-27.

Artículo recibido: 03 de marzo de 2017; aprobado: 05 de mayo de 2017 


\section{Introducción}

En este trabajo abordaremos, desde perspectivas metadidácticas y hermenéuticas, la comunicación literaria infantil (CLI) en su doble papel de objeto sociodidáctico y literario. Para ello, trataremos de sentar las bases de ese objeto complejo (Morin, 1998, 2004) y transdisciplinar (Nicolescu, 2002) que conforma el sintagma literatura infantil.

Antes de continuar aclararemos los conceptos sobre los que pivota este artículo: 1) metadidáctica, 2) hermenéutica analógica, 3) sociodidáctica y 4) comunicación literaria infantil.

Podemos definir metadidáctica como una metateorización (teorización de una teoría) de la didáctica y su estudio. Dicha reflexión constituye un sistema de conocimientos y capacidades metacognitivos, los cuales pretenden indagar y perfeccionar la disciplina didáctica. En lo que respecta a las metadidácticas específicas, la reflexión está orientada a preservar y desarrollar los fundamentos didácticos de una disciplina concreta (en nuestro caso, la literaria).

Por su parte, la hermenéutica de Beuchot (2000, 2004, 2008) se fundamenta en una premisa interpretativa flexible, que tiene en cuenta el equilibrio entre objetividad y subjetividad. La analogía define este cruce entre la univocidad y la equivocidad, ofreciendo un espacio epistemológico muy adecuado a la investigación didáctica y metadidáctica.

En cuanto al término sociodidáctica, se incide en el carácter social de la educación y la realidad aularia, entendida esta como subsistema regido por las dinámicas de todo grupo social.

Por último, consideramos la CLI como comunicación de plena adscripción literaria, cuya especificidad viene dada, en esencia, por su receptor. Si bien se dirige a un destinatario de edad determinada, no está segregada de la literatura en general, y

si se le añade infantil [...] es por la necesidad de delimitar una época concreta de la vida del hombre que, en literatura, está marcada por las capacidades de los destinatarios lectores $y$, en menor medida, por gustos e intereses lectores [...], así como por sus posibilidades de recepción literaria. (Cerrillo y Sánchez, 2006, p. 17)

De lo anterior se deduce que sus características (sencillez de estructura y narración; unidad espacio-temporal; escasez de descripciones; cronología lineal; reducción o supresión de historias secundarias; simplificación de personajes; vocabulario accesible; unidades temáticas breves; importante carga afectiva; tendencia a la humanización; colaboración texto-imagen; etc.) vienen determinadas por la adecuación al destinatario, y no han de mermar su calidad literaria.

Desde estos planteamientos, reflexionaremos sobre las nociones de metadidáctica y hermenéutica aplicada al aula. Continuaremos por revisar la interpenetración entre las disciplinas literarias (con especial hincapié en la sociología de la literatura) y las áreas de conocimiento implicadas en la infancia y la didáctica. Dicha labor pondrá al descubierto la complejidad de la CLI, y dará paso a una reflexión sobre el docente como mediador.

En este sentido, reflexionaremos sobre el papel de la LI en el ámbito universitario. Este planteamiento, que involucra a docentes y estudiantes, entronca con las investigaciones sobre el pensamiento del profesor. Este campo considera que toda actuación didáctica está fuertemente condicionada por las ideas que el docente tiene acerca del objeto de enseñanza y el proceso de aprendizaje que este implica (Munita, 2013)

Todo lo anterior pone de relieve la necesidad de observar e interpretar los conocimientos y percepciones que los futuros maestros tienen sobre la $\mathrm{LI}$, el proceso de intermediación entre esta y el niño, y su función como potenciales agentes mediadores.

\section{Aproximación epistemológica y metodológica}

"La complejidad, la diversidad y la interactividad propia de las situaciones socioeducativas refleja la 
urgencia de adoptar prismas diferentes en la teoría y en la praxis científica" (Suárez, 2005, p. 13). Vivimos en un contexto altermoderno (Bourriaud, 2009) y complejo, en el que escuela y universidad deben hallar un equilibrio entre positivismo y relativismo. En este sentido, entendemos que la hermenéutica analógica (HA) de Beuchot (2000, 2004, 2008) brinda el adecuado paraguas epistemológico y metodológico para aunar teoría y práctica del hacer y pensar didáctico. Junto a ella, la metadidáctica se consolida como epistemología de segundo orden, capaz de afrontar realidadescomplejas y transdisciplinares.

Tal perspectiva permea teoría y praxis en un doble sentido: en la comunicación literaria infantil en sus aspectos sociales, didácticos y literarios, y en lo relativo al texto aulario superior de educación. Este artículo pretende abrir camino, en sendas direcciones, a posteriores investigaciones prácticas. Dicha intención responde a una dimensión sociocomunicativa e indagadora de la ciencia didáctica, y tiene como objetivo servir de base metateórica para sus dimensiones aplicativa, normativa y artística.

La metodología está basada en un estudio decaso, consistente en el análisis hermenéutico continuado del cuarto y último curso del grado de Educación Infantil de la Facultad de Soria. Los planes de estudio de la Universidad de Valladolid incluyen la literatura infantil como asignatura obligatoria de la mención de lengua inglesa, siendo optativa para los estudiantes de la rama generalista.

La elección de este curso se debe a que las alumnas $^{1}$ ya han pasado por asignaturas relacionadas con la didáctica de la lengua. Se trata, además, de estudiantes a punto de iniciar su vida laboral.Sin embargo, constatamos que, tras haber cursado dos años antes una didáctica de la lengua oral y escrita, continúan respondiendo a una fuerte instrumentalización curricular de la LI. Obvian,

1 Especificamos el género debido a la importante feminización de los grupos, en los que a veces no hay ningún alumno o, a lo sumo, dos o tres en los grupos de mayor representatividad masculina. engeneral, la calidad literaria de las obras infantiles para atender casi exclusivamente al didactismo. Es, pues, necesario insistir en el sustantivo literatura para evitar que quede eclipsado por el adjetivo infantil.

Ha sido a partir de la experiencia y reflexióndidácticas como hemos concluido en la necesidad de una reflexión metadidáctica en torno a la CLI, su enseñanza superior y el pensamiento de docentes universitarios y futuros maestros. Entendemos que la educación literaria se encuentra estrechamente relacionada con las creencias, representaciones y saberes (Ballesteros et al., 2001) de los profesores, por lo que consideramos importante una modificación o refuerzo positivo de este imaginario o sistema CRS. En dicha tarea parece esencial insistir en el carácter literario de la obra infantil.

El corpus de textos infantiles utilizado toma como referencia la vida lectora infantil del alumnado, con el fin de partir de su intereses y sus nexos emocionales. Esto responde a una búsqueda de didáctica experiencial, que entendemos ayuda a establecer nexos afectivos con el texto, además de permitir a la docente adentrarse en las inquietudes y gustos de las estudiantes. La elección de las obras que les han marcado más tiene la intención de ir transformando su saber implícito en explícito.

Es difícil, por consiguiente, ofrecer un listado de los textos que se manejan, tanto en estas primeras sesiones como más adelante. Pero es interesante señalar que las alumnas acuden en su mayoría a cuentos clásicos, las más de las veces relacionándolos con Disney en lugar de atenerse a las versiones originales. Esto da pie a reflexiones sobre el imaginario literario, audiovisual y sociodidáctico, que se verán implementadas con el análisis posterior de álbumes pensados para niños y niñas entre 3 y 6 años de edad. La premisa es que el aspectosocial y didáctico no excluya ni merme el literario.

El corpus de obras estudiadas en el aula trata de atender a un amplio abanico de obras, 
pertenecientes a todos los géneros literarios. Estas van desde los ejemplos más canónicos de la LI, hastalas novedades editoriales, que responden a criterios de calidad y diversidad. Se analizan: cuentos de hadas y maravillosos (así como sus versiones); clásicos contemporáneos; la llamada literatura de género o antiautoritaria; el cómic para niños y álbumes exclusivamente ilustrados; los libros-objeto o libros-juego, y su comparativa con los textuales; las obras de no ficción; textos basados en pictogramas; etc.

La imbricación entre teoría y praxis es esencial en tales análisis, así como una reflexión metadidáctica basada en la hermenéutica analógica. Esta perspectiva interpretativa se fundamenta en un aumento de la comprensión gracias a la observación continuada de los procesos de enseñanza/aprendizaje. Esto revierte tanto en la práctica docente como en la investigación. El proceso está representado por la espiral hermenéutica, que plasma gráficamente la ampliación y profundización gradual del conocimiento. La comprensión de los inputs existentes genera, a su vez, la precomprensión de unos nuevos para profundizar otra vez en estos últimos y producir una comprensión diferente.

Se trata de un proceso de constante retroalimentación entre teoría y práctica, en el que esta revierte en la mejora de aquella, y viceversa. Es obvio que tal conocimiento no puede seguir un itinerario fijo, pues la realidad aularia no es un sistema estático. Como subsistema sociodidáctico, se encuentra sujeta a sus particulares dinámicas, determinadas por las variables textuales y contextuales.

Superadas las corrientes investigadoras basadas en el proceso/producto, es obvio que discentes y docente escriben el texto aulario, a analizar hermenéuticamente a partir de esta tríada comunicativa (autor/ texto/lector). El presente artículo atiende además al pensamiento del profesor, o teacher's mental lives (Borg, 2009), como factor contextual no observable, que incide en la intención y acción didácticas. Tal perspectiva está relacionada con el sistema de creencias, saberes y representaciones, tanto en lo que respecta al docente universitario como a sus estudiantes y futuros maestros.
Hemos visto que, en su carácter cualitativo-interpretativo, la hermenéutica analógica establece comparativas comprensivas, gracias a la continuidad de los procesos investigadores. El análisis parte de una prudente aplicación entre objetividad y subjetividad, donde analogía y sutileza devienen en una permanente atención a verdades entre lo unívoco y lo equívoco. Dichas verdades vendrán matizadas por la interpretación de las variables sociodidácticas del texto y contexto aularios. El texto incluye el número de alumnos, sus identidades y nivel académico, valores y relaciones entre ellos, temporalización y secuenciación de sesiones, curso, interacción docente/discente, etc. Por su parte, el contexto estará conformado por las circunstancias externas al aula, como los factores culturales y socioeconómicos. Permeando texto y contexto se encuentra el imaginario sociodidáctico compartido, así como las creencias y saberes individuales y grupales.

Es claro que ambos incidirán directamente en la realidad de enseñanza/aprendizaje. Por ello, entendemos que el carácter flexible, prudente y sutil de la hermenéutica analógica, así como su vocación dialógica entre razón e intuición, brinda una metodología flexible, subjetiva pero controlada (Flick, 2004), adecuada a la investigación didáctica y metadidáctica. Basada en la sutileza (o subtilitas) hermenéutica, establece las fases intelligendi (implicandi, para Beuchot); explicandi y aplicandi, como profundización y puente entre la reflexión y aplicación.

\section{Metadidáctica y hermenéutica del aula}

Parece obvio que todo docente no solo es coautor y correceptor del texto aulario y hermeneuta que lo interpreta, sino científico que guía procesos didácticos teóricos y aplicados. Esta tarea implica pensar el aula como texto a interpretar y espacio de reflexión e investigación (Ballesteros et al., 2001; Camps, 2001).

Además de los procesos de enseñanza/aprendizaje de cualquier clase, en las aulas superiores 
de educación tienen lugar dinámicas de comunicación y reflexión metadidáctica sobre la teoría y praxis de los maestros. Esto requiere de una hermenéutica analógica que interprete el proceso docente/discente.

A la complejidad del objeto de estudio se suman las dinámicas de toda investigación interpretativa educacional en dos aspectos. El papel socializador de la LI, así como la concepción que los futuros maestros tienen de ella, implican a la didáctica en: a) su relación con el niño y el contexto social y escolar, y b) respecto al estatus de la enseñanza de la CLI en las facultades de Educación.

Si describimos metateoría como la disciplina que estudia la teoría de un área de conocimiento, las interacciones docentes/discentes habrán de atender no solo a dimensiones formales y fácticas, sino también a aspectos de corte filosófico, como recogen Rodríguez y Colom (1996) en alusión a Pérez Gómez. La metadidáctica, como espacio de transferencia entre utens y docens, trasciende el ámbito normativo y aplicativo de la ciencia didáctica, en una fusión que ayuda a comprender plenamente lo educativo.

Además de la interacción entre didáctica y ciencias de la educación, la comprensión del proceso de enseñanza/aprendizaje requiere de una epistemología que siente las bases de la ciencia didáctica. Explorar estos fundamentos implica una aproximación a la filosofía (Azerêdo, 2003) de la educación, la cual tendrá como tarea validar la ciencia didáctica desde esa organicidad teórica-empírica.

Asumimos, con Puig y Salabarría (2009), la metadidáctica como epistemología capaz de abordar el estudio de objetos multidimensionales. Esto responde a nuestra idea de la metadidáctica como integradora de la dualidad epistémica propuesta por Colom (1992): la perspectiva epistemológica pragmatista-utilitarista de la teoría de la educación, y la racional de la filosofía de la educación.

Entendido el texto aulario como interacción sociodidáctica, es necesario interpretar el aula como sistema orgánico y organizado:
La clase, de hecho, responde a los requisitos típicos que los sociólogos exigen a un grupo de individuos para poder usar la denominación "sociedad" (Robertson, 1977, p. 83). Dichos requisitos son: ocupan un "territorio" común (el aula la escuela), interactúan entre ellos, saben que pertenecen al mismo grupo, tienen, al menos en parte, una cultura común (D'Amore, Font y Godino, 2007, p. 54).

Como se ha encargado de demostrar la etnografía aplicada, el aula constituye una microsociedad regida por sus particulares normas y metanormas.

El prefijo meta remite asimismo a una episteme altermoderna (Bourriaud, 2009), esto es, entre modernidad y posmodernidad. Tal vocación analógica confirma la necesidad de un modelo integrador y sistémico de investigación aularia.

De lo anterior se deduce que la metadidáctica es:

1. Altermoderna, porque recupera un prefijo (meta) esencialmente moderno, pero abandona la hiperbolización del objeto positivista para integrar metaciencia y subjetividad; metaconocimiento y relativización o (mejor) jerarquización analógica de la(s) verdad(es); univocismo y equivocismo. Esto nos lleva a las siguientes características epistemológicas:

2. Sistémica y compleja: entiende la investigación como sistema orgánico (holón) que incluye varios subsistemas (holones) interrelacionados. Además da cabida a la complejidad como cualidad del objeto de estudio. La investigación está, así, definida por la transdisciplinariedad. Todo esto le confiere un excepcional carácter:

3. Integracionista: su esencia, ya de por sí integradora de disciplinas y epistemes, se ve potenciada por el prefijo meta. Como metaciencia, su finalidad es llevar a cabo un análisis crítico de las teorías precedentes y sus vínculos con otras ciencias, además de pensar los procesos de construcción de 
conocimiento y conceptualización (Puig y Salabarría, 2009).

Podríamos argüir, por tanto, que el sustrato filosófico y metateórico se pone al servicio de una reflexión sociodidáctica, que explore los fundamentos epistémicos de la metadidáctica y la refuercen como ciencia.

Creemos, además, que su carácter analógico fundamenta su naturaleza procesual, traspasando con sutileza las capas de la teoría y práctica de la ciencia didáctica.

Por otro lado, y si bien la ciencia didáctica tiene un carácter integrador entre acción y reflexión, su vocación aularia la lleva habitualmente hacia tendencias más prácticas que teóricas. No obstante, la metadidáctica insiste en el carácter holístico del hecho educativo, como

[...] vía de transición y establecimiento de los vínculos entre los conocimientos teóricos que tienen una dimensión filosófica ${ }^{2}$ y aportan una reflexión generalizadora sobre el fenómeno didáctico en conjunción con los conocimientos empíricos específicos que proveen las Ciencias de la Educación, las Ciencias Pedagógicas y aún más en concreto la Ciencia Didáctica. (Puig y Salabarría, 2009, p. 51)

Lo expuesto lleva a concluir que, como mediador de procesos y objetos complejos, el análisis del docente y sus CRS requiere de esta perspectiva metahermenéutica y metadidáctica. También la CLI como objeto de estudio complejo y su función de puente entre la comunidad, el propio mediador y el niño.

A tal efecto, resulta necesario ampliar la didáctica al universo teórico y metateórico literario. Tradicionalmente, la didáctica de la literatura ha dialogado con las ciencias filológicas y educativas. Pero existen múltiples aproximaciones disciplinares a la literatura, como la estilística, la sociología,

2 Desde nuestro enfoque, sería más preciso aludir a esta dimensión filosófica como dimensión metateórica. el psicoanálisis, la hermenéutica o el comparatismo (Llovet et al., 2012).

La dimensión cultural de lo literario implica que materias como historia o filología resulten insuficientes para explicar el objeto literario. Consecuentemente, parecería pertinente una ampliación de los estudios literarios en el seno de la didáctica, que abriera el foco a todas las disciplinas literarias de modo horizontal. Entendemos que esta mirada no jerarquizada aportaría interesantes visiones al análisis sociodidáctico de la CLI, así como al estudio de la mediación docente.

\section{La comunicación literaria infantil}

La literatura infantil requiere pues de un abordaje multidisciplinar. Participa de la historia y teoría literarias, el comparatismo y la tematología, la didáctica, la filología, sociología, psicología, pedagogía, lingüística, ética, estética. Por otro lado, su particular recepción dota a las obras de una doble condición: la de objetos literarios y educativos. Tal especificidad da lugar a una teoría y praxis problemáticas, con numerosas tensiones entre literatura y escuela. Hagamos una breve revisión al respecto.

Croce (1985), quien presuponía al menor incapaz para captar los valores estéticos de la obra, no solo negaba a la LI toda categoría artística, sino que relegaba su recepción a un proceso denotativo (ausente de toda connotatividad poética). En su rechazo del arte con adjetivos incluía el de infantil. Autores como Carandell (1977), Rico (1986) o los mismos Juan Ramón Jiménez y Rafael Sánchez Ferlosio tampoco legitimaron su existencia.

Amparados en la calidad artística como argumento, los detractores del hecho literario infantil denunciarían lo que consideraban la falacia de este. En general fundamentan en la competencia estética la categorización de producto artístico, y entienden que un lenguaje sencillo, adaptado al lector infantil, suprime toda posibilidad de literariedad. Por ende, dudan o niegan categóricamente no solo la conveniencia del marbete, sino la misma existencia de la LI. Se genera un debate en torno a una pregunta: 
si algo es literatura, ¿a qué fin añadirle cualquier calificativo?

Entre los defensores de la LI y su especificidad, autores como López (1990) alegaron que "la adecuación a la infancia" no es, en ningún caso, "negación del arte". En la misma dirección, Verdulla (1998) daba por supuesta la LI, y argumentaba la necesidad didáctica de obras destinadas a la infancia, pues el niño exige "experiencias de lengua apropiadas" y "requiere una literatura que avance igual que él y su entorno avanzan" (p. 8). Bortolussi (1987) abogaba por una "verdadera literatura infantil" a partir de una superación histórica: el abandono de actitudes didácticas y pseudoliterarias, responsables de que "rara vez" los cuentos infantiles superaran "el estatuto de agentes de socialización" (Bortolussi, 1987, p. 1).

A esta postura podemos añadir a Merlo (1976), Cervera (1984, 1989, 1992), Sánchez (1992, 1995, 1999), Mendoza (1999), Cerrillo y García (1999, 2000), Cerrillo, Larrañaga y Yubero (2002), Cerrillo y Sánchez (2006), Lluch (2003), Del Amo (2003), Tabernero (2005), Lerer (2009), Colomer (2010), Morales Lomas y Morales Pérez (2011), por nombrar algunos de los muchos autores que defienden la especificidad de la LI.

En la actualidad pocos niegan su legitimidad. El debate teórico entre calidad literaria e instrumentalización didáctica parece superado. Sin embargo, podemos afirmar que, en la práctica, tal dicotomía es aún responsable de gran parte de las tensiones entre literatura y didáctica.

En este artículo damos por superada la vieja polémica, y partimos de la anteposición de lo literario sobre cualquier instrumentalización, ya sea curricular, psicopedagógica o socializadora. Es importante dejar clara esta postura, pues damos por sentada la especificidad de la LI para, desde este punto, observar su importancia sociocultural y didáctica.

De tener alguna finalidad esta es [o debería ser] "promover en el niño el gusto por la belleza de la palabra, el deleite ante la creación de mundos de ficción" (Merlo, 1976, p. 78). Tal perspectiva enfatiza la dimensión estética de la "obra artística destinada al público infantil" (Bortolussi, 1987, p. 16). No olvidemos que teóricos como Culler (2000) señalan precisamente la falta de utilidad práctica de los textos literarios como posible cualidad de estos.

En su investigación sociológica de la literatura infantil y juvenil, Morales Lomas y Morales Pérez (2011) destacan su carácter de producto estético. Conscientes de la especificidad de su destinatario, insisten en que "al igual que cualquier creación artística [...] es antes que nada un hecho de creación estética" (p. 31).

Partimos, pues, de que la LI es literatura de pleno derecho. Ahora bien, no contemplamos la literatura instrumentalizada (Cervera, 1989) o los productos paraliterarios basados en series puerilizantes, en el sentido que Rico (1986) le da a productos de escasa calidad, destinados a prolongar fútilmente la infancia. Tampoco observamos aquellos sujetos a intenciones pesudodidácticas, herederos de una tradición basada en la el adoctrinamiento, los exemplas y otras enseñanzas moralizantes que despojan a la LI "de los únicos valores que le son exigibles [...]: los literarios" (Cerrillo y Sánchez, 2006). Excluimos asimismo las imposiciones mercantiles no literarias, fruto de las promociones comerciales audiovisuales; también aquellas obras que, enmascaradas tras elementos paratextuales infantiles, ocultan un discurso adulto. El debate es amplio y excede este artículo. Pero, para hablar de literatura infantil, tanto adjetivo como sustantivo han de ser tenidos en cuenta, como garantía de calidad artístico-cultural o lúdica pensada para el niño.

La complejidad de la CLI y su hermenéutica requieren, como se ve, de la transdisciplinariedad, tanto para su sistematización teórica como para interpretar los discursos que suscita. La obra literaria infantil participa de las cualidades que distinguen el discurso literario del estándar, y que el formalismo tratara de aislar bajo el nombre de literariedad. Pero tal extrañamiento poético no le exime de su "función socializadora de las nuevas generaciones" (Colomer, 2010, p. 49).

Como toda obra literaria, es materialización de unos imaginarios compartidos, que buscan ser transmitidos. La LI tiene como funciones: 
Iniciar el acceso al imaginario compartido por una sociedad determinada.

Desarrollar el dominio del lenguaje a través de las formas narrativas, poéticas y dramáticas del discurso literario.

Ofrecer una representación articulada del mundo que sirve como instrumento de socialización de las nuevas generaciones. (Colomer, 2010, p. 15)

Este triple objetivo pone en contacto tres grandes áreas de conocimiento: literatura (en sus aspectos histórico, teórico y comparatista), sociedad y didáctica. Dicha confluencia posibilita una metateoría literaria y sociodidáctica para el estudio de la LI como objeto educativo y de inserción cultural, social y artística.

\section{Sociedad y comunicación literaria infantil. El docente como mediador}

Entre los excesos del determinismo dialéctico y el inmanentismo, el carácter de hecho sociocultural de la obra literaria propone las dialécticas de: a) texto/contexto, b) expresión cultural/social/individual, c) hecho estético/ideológico/creativo y d) diálogo (y problemática) entre ciencias humanas y sociales. Las dualidades se vehiculan entre sí, por cuanto la literatura es: a) producción artístico-cultural; b) fruto y manifestación de lo social y c) creación individual. Por ende, es expresión estética e ideológica individual y colectiva, y constructora de realidades personales, sociales y culturales, o pretendiente a serlo.

Como ciencia interdiscursiva, la sociología de la literatura busca la superación interdisciplinar del mito de inmanencia (el texto como hecho aislado de todo contexto) y el principio de literariedad. Ahora bien, lo interesante es que mantiene vivo su objetivo de analizar las relaciones entre autor, texto y sociedad (si bien la división en tres instancias es ilusoria, pues, según su perspectiva, la lógica social penetra en los elementos de la tríada comunicativa ab initio). Entendemos que a la vez fortalece los análisis sociológico y literario, al estudiar las condiciones sociales de la producción y recepción de las obras sin olvidar su dimensión estética.

Algunos autores muestran "una clara conciencia de la extrema complejidad del dominio de conocimiento que es la realidad social que llamamos literatura" (Chicharro, 2005, p. 39). Reconocen

[...] la legítima existencia de los diversos paradigmas en que se asienta hoy el saber literario (semiológico, sociológico, psicoanalítico, fenomenológico), así como la necesidad de poner en diálogo teórico dichos paradigmas para procurar avanzar cualitativamente en el proceso de construcción de un saber complejo. (Chicharro, 2005, p. 41)

"Hay, por lo menos, tres mil maneras de explorar el hecho literario", diría Escarpit (1971, p. 5). Partimos, pues, del "carácter proteico y cultural de la propia literatura" (Llovet et al., 2012, p. 23), para insistir en su problemática.

Como vemos, el binomio literatura + infantil parte de dos objetos marcados por una profunda multidimensionalidad: "Si ambiguo resulta el término literatura, no lo es menos el adjetivo infantil. Así, literatura infantil, desde su denominación, suma dos ambigüedades. Es lógico que la fusión de ambos términos aboque a una realidad también ambigua" (Cervera, 1992, p. 11).

Creemos necesario afrontar la relación entre LI y didáctica en términos dialógicos. Como en todo complexus, las partes forman un continuum indivisible. La ecuación cobra su sentido en una transdiciplinariedad que no solo atraviesa las distintas disciplinas, sino que va más allá de todas ellas. Por tanto, la construcción y recepción del conocimiento se basa en una relación interactiva entre las áreas que la integran.

Como hemos apuntado, tal complejidad está fuertemente determinada por la naturaleza de su receptor. Lo recuerda entre otros Sánchez Corral (1999), quien apela a la estética de la recepción para establecer una correlación entre emisión y recepción que consideramos básica: el niño como eje del proceso comunicativo. El respeto hacia 
este debería regir la producción, distribución y elección de las obras infantiles, tanto en los circuitos de edición como en los culturales y educativos. Es aquí donde la figura del mediador se torna imprescindible.

En su análisis pragmático en torno a la narrativa infantil, Lluch (2003) alude a algunas singularidades del proceso comunicativo literario infantil. La consideración de la infancia en el momento histórico-social determinado; la enseñanza y sus métodos; el libro y el papel que desempeña en una sociedad... vertebran su estudio. La autora enfatiza la interacción entre un autor adulto y un lector niño para destacar algunos elementos diferenciadores de la LI. De un modo u otro, esta comunicación está mediatizada "por la relación social que históricamente ambos [autor y lector] mantienen [...]. Estas especificidades establecen algunas diferencias con el resto de literaturas" (Lluch, 2003, p. 27).

Escarpit (1971) insiste en la complejidad del circuito de intercambio literario. La sociología de la literatura contempla el proceso desde una perspectiva trascendente, es decir, con una vocación que trasciende el marco lingüístico del texto.

En cualquier punto del circuito, la presencia de individuos creadores plantea problemas de interpretación psicológica, moral, filosófica; la mediación de las obras plantea problemas de estética, estilo, lenguaje, técnica y, finalmente, la existencia de una colectividad-público plantea problemas de orden histórico, político, social, incluso económico (Escarpit, 1971, p. 5).

Esta trascendencia implica una complejidad que excede los límites discursivos. En su nombre, Escarpit reclama que los exploradores de la literatura tengan una visión completa y no deformada. Entendemos que tal exigencia pasa por la construcción de una transdisciplinariedad que afronte la tarea desde perspectivas complejas no jerarquizadas.

Como vemos, la sociología de la literatura aporta interesantes reflexiones en torno a los procesos de producción, distribución y recepción de la
CLI, su hermenéutica y metateoría sociodidáctica. Claro que estas obras participan de mecanismos sociales y de mercado semejantes a toda comunicación literaria, pero sus particularidades exigen una sociología literaria específica, que se ajuste a un proceso comunicativo literario diferenciado: una sociología de la literatura infantil que explique el texto atendiendo al contexto literario, infantil y sociodidáctico. El aula, por tanto, habría de ser objeto de la misma, como holón o subsistema social de pleno funcionamiento (Francisco Carrera, 2016) donde se establecen procesos socializadores y didáctico-literarios.

La recepción de la LI no solo es clave por su especificidad, sino porque en ella, "a diferencia de otras literaturas, a menudo [el receptor] es doble" (Lluch, 2003, p. 27). El debate sobre la existencia de un doble destinatario y las diferencias entre receptor y destinatario es antiguo. Pero es un hecho que "los libros son producidos por los adultos y también son ellos quienes gobiernan la incorporación de las nuevas generaciones al diálogo cultural" (Colomer, 2010, p. 61). El proceso de producción, distribución y recepción de la CLI implica al adulto no solo en los mecanismos de autoría, edición, mercado, etc., sino como filtro decisivo entre el texto (y su imaginario) y su lector.

En síntesis, la CLI parte de un autor (adulto), el cual supuestamente trata de obtener un tipo especial de extrañamiento (a veces pseudoinfantil), para llegar a un receptor (el niño) que no siempre es en primera instancia quien elige el texto (infantil o parainfantil) y que ha de decodificarlo o ser ayudado para esta decodificación. En este itinerario aparecen, junto a los mecanismos de difusión, aspectos tensionales entre literatura, pedagogía y mercado, así como una figura que añade al proceso una complejidad nueva: la del mediador o intermediario.

Encarnado en diferentes instancias (padres, maestros, bibliotecarios, leyes educativas, editoriales, librerías, medios de comunicación...), este cumple una función a caballo entre el niño y el imaginario muy interesante. En todos estos 
ámbitos sociales donde los niños y las niñas se encuentran con los libros [...] se produce una tensión entre, por un lado, el control de lectura por parte de los adultos [...] y, por otro lado, la libertad de elección y del uso del libro por parte del lector infantil. Si la mediación cultural tiene éxito, si los niños y niñas se interesan por los libros, aprenden a leerlos y se familiarizan con la forma en la que circulan socialmente [...], su autonomía para escogerlos progresará paulatinamente hasta su completa independencia en la vida adulta. (Colomer, 2010, p. 61)

El papel de mediador puede determinar, entonces, no solo el acceso inmediato al libro, sino la futura experiencia lectora, con lo que tal ascendencia implica. Nos hallamos ante una manifestación cultural esencial para la educación y el crecimiento intelectual, social, ético y estético del ser humano. No solo porque "es a través del lenguaje y el cuento que se promueve la cognición" (Zipes, 2014, p. 32), sino porque difícilmente encontraríamos en nuestro panorama cultural un objeto más útil que la literatura para la formación del ciudadano y el espíritu del demos (Llovet et al., 2012).

La figura del mediador merece, entonces, una profunda atención. Lluch (2003) diferencia tres tipos de mediadores: los institucionales, los editoriales y los educativos. Serán estos últimos los que centren nuestro interés metadidáctico.

Hace ya décadas que Cervera, tras constatar la escuela como excepcional agente del libro infantil, señalaba la considerable instrumentalización que este suele experimentar desde preescolar. El exceso de funcionalismo todavía parece ser uno de los grandes riesgos, pues tanto entre los actuales como futuros maestros persiste un utilitarismo que eclipsa la dimensión literaria. El peligro de un abusivo didactismo ha sido puesto de relieve por autores como Colomer (2010) o Borda (2002). En líneas generales, "los docentes no han sido capaces de renunciar a lo didáctico, y no se han atrevido a proponer lecturas o relatos simplemente por proporcionar a sus alumnos eso que Sánchez
Corral (1995) Ilama 'la aventura de lo excepcional' que aporta la ficción" (Núñez, 2009).

Así, si bien en la teoría parecen haberse superado antiguas polémicas, en la práctica subsisten tensiones entre literatura prescriptiva o lectura libre; novedades editoriales o canon; alta literatura versus baja literatura; los clásicos como punto de partida o de llegada; el fenómeno best-seller frente a la preservación del imaginario compartido; lecturas imprescindibles o goce lector...

La didáctica de la literatura no parece haber encontrado respuestas incontrovertidas a determinadas problemáticas. Cómo hacer que los niños lean es solo la primera de una batería de preguntas difíciles de responder taxativamente. Es aquí donde el maestro y su sistema CRS sobre la LI adquiere gran importancia.

\section{Conclusiones}

Parece, pues, imprescindible en las facultades de Educación una revisión metadidáctica, sistemática y continuada en torno a la CLI y su uso en las aulas. Asimismo, y dado el generalizado abuso del didactismo entre futuros y actuales maestros, resulta necesario un trabajo ponderado sobre las creencias, representaciones y saberes de los estudiantes, de cara a una mejora de su educación literaria. Dicha tarea pasa por la implicación, explicación y aplicación de los saberes implícitos y explícitos de docentes y discentes, con el fin de que su modificación e incidencia revierta en sus futuras intenciones y acciones didácticas.

Apostamos por una hermenéutica basada en un equilibrio entre los aspectos didácticos y su dimensión literaria, así como entre objeto y sujeto. Esto es, una metodología interpretativa flexible y sutil. Asimismo, entendemos que la CLI, como proceso literario muy determinado por la naturaleza de su receptor, requiere para su exégesis de una hermenéutica específica.

En las aulas superiores de educación, la puesta en marcha de reflexiones conjuntas habrá de sentar los fundamentos de la praxis, aportando una base 
teórica a la didáctica aplicativa y normativa. Así, y junto a la hermenéutica como epistemología de primer orden, la metadidáctica se constituye epistemología de segundo orden, desde la que abordar holísticamente un texto aulario previamente comprendido con herramientas hermenéuticas.

En este sentido, hemos comprobado que la reflexión sociodidáctica y literaria en facultades de Educación incide positivamente en las creencias y saberes de los futuros maestros respecto a la educación literaria y la LI. Entendemos que es positivo partir de una didáctica experiencial, basada en la vida lectora y discente del alumnado. Ello desemboca en una mayor vinculación afectiva con los textos y la experiencia lectora (San Juan, 2011), que impulsa la enseñanza/aprendizaje. Entendemos que el saber implícito revierte en el saber explícito, para desembocar en un análisis hermenéutico y metateórico en torno a lo literario y lo didáctico. Dicha interpretación hace reflexionar al alumnado sobre el valor no instrumental de la LI.

Tal itinerario sigue las fases hermenéuticas de la subtilitas, pues parte de la implicación como antesala de la explicación para después llegar a la aplicación. Todo ello acompañado una progresiva profundización comprensiva, que al final del proceso establecerá una comparativa entre el inicio y el final de la intervención e investigación didáctica.

Es necesario destacar que, en el caso de los lectores fuertes, el proceso de reflexión es más rápido y eficaz, dado que en su sistema de creencias y saberes la literatura ocupa un espacio más preeminente.

Dada la multidimensionalidad del binomio $/ i$ teratura + infantil, entendemos perentoria una apertura transdisciplinar y una revisión de criterios didácticos. La enseñanza de la LI en las facultades de Educación sigue en muchas ocasiones sujeta al perfil profesional y los intereses filólogos, teóricos, didactólogos, etc., de quien la imparte. La formación de mediadores debe aunar conocimientos sobre literatura, lectores y libros infantiles (CerriIlo, Larrañaga y Yubero, 2002). En este sentido, la horizontalidad entre las disciplinas literarias y sociodidácticas contribuirá a superar en la práctica el debate entre calidad literaria e instrumentalización de la obra infantil.

Dada la influencia de la LI en el niño, consideramos imprescindible análisis profundos sobre la percepción que de la intermediación docente tienen los futuros maestros. Desde nuestra experiencia docente, constatamos el riesgo de que el utilitarismo curricular eclipse el goce estético. Prueba de ello es la reiteración por parte de nuestro alumnado de oraciones como "este libro sirve para", "lo utilizaremos para trabajar", seguido de un aprendizaje contenidista, actitudinal, procedimental, etc.

Entendemos que tales representaciones nacen de una lógica didáctica en la que el estudio curricular pesa sobre la reflexión metadidáctica. Es habitual encontrar en nuestras escuelas visiones de la literatura impregnadas de pragmatismo pedagógico, en las que la competencia lectora o cognoscente y la búsqueda de valores parecen dejar de lado todo sustrato literario. Pero,

obras de la literatura infantil y juvenil [...] tienen valor y entidad en sí mismas, son entidades semióticas de categoría estética y su funcionalidad no es necesariamente la de servir de vía secundaria de acceso a la "gran literatura"; más bien hay que destacar y matizar que sirven para formar al individuo como lector [...] precisamente porque en estas obras las cualidades semióticas de la (gran) literatura ya está en ellas. (Mendoza, 1999, p. 11)

Cuando Lerer (2009) señala que la historia de la LI es como si "tuviera que ser escrita entre los espacios que dejan libres los maestros, como si siguiera siendo meramente una versión torpe y simplista de una obra 'adulta' " (p. 24), está alertando de los peligros de dicho utilitarismo, y de la marginalidad a la que incluso en la escuela ha estado sometida la LI. A dicho utilitarismo se une el económico, pues como era de esperar, los libros para niños no han escapado a las poco sutiles pero eficaces redes del consumo. 
Por su parte, las Ilamadas disciplinas serias o canónicas de lo literario han otorgado tradicionalmente a la LI un carácter de expresión periférica y hasta inexistente. Por fortuna, tal perspectiva ha cambiado desde hace algunos años. Hoy casi nadie se atreve a negar la literatura para niños. Pero si bien ya se cuenta con trabajos de gran rigor teórico, entendemos que la deuda por parte de los estudios literarios con la LI continúa vigente.

Es un hecho que la teoría pedagógica ha prestado más atención a la LI que la literaria. No en vano la obra infantil nació de intenciones didácticas e ideológicas, y aun hoy día su estatus académico forma parte de los planes de las facultades de Educación pero no de los estudios filológicos o teóricos. Con el tiempo, la tensión entre pedagogía y calidad fue reduciendo distancia. Pero si bien la mayor parte de la teoría ha decidido dar por superada la dicotomía pedagógico-literaria, aún se manifiesta de una forma u otra en la práctica editorial, educativa y crítica.

La literatura infantil y juvenil en los últimos años posee una componente didáctica y pedagógica que le está restando credibilidad y está ahogando el hecho literario [...] al albur de lo que dice la pedagogía y no lo que dice la literatura. (Morales Lomas y Morales Pérez, 2011, p. 66)

La didáctica y la innovación pedagógica tratan, no obstante, de solucionar las fricciones relacionadas con el ámbito escolar. $\mathrm{Y}$ aunque su servidumbre curricular les lleva en no pocas ocasiones a reincidir, es necesario subrayar que los avances en materia didáctica han ido de la mano de una nueva LI, que da lugar a obras adecuadas al niño y sus necesidades lectoras y cognitivas sin olvidar la calidad y evolución de su competencia literaria.

Insistimos en que entendemos fundamental una adecuada percepción de los estudiantes de educación en torno a la CLI. Ellos serán quienes decidan en gran medida el presente y futuro lector del niño. Con este fin, parece imprescindible potenciar entre la comunidad educativa universitaria mecanismos de reflexión sobre su responsabilidad en el proceso de intermediación entre a) el niño, b) el libro y c) el imaginario (como tríada o como dualidad de a en su interacción con b) o c) requiere de análisis en continúa revisión y profundidad.

En este sentido, "la introducción de secuencias de reflexión sería muy productiva en el diseño de la formación de mediadores en el área de la formación literaria" (Silva-Díaz, 2001).

Por otra parte, si la LI supone el acceso del individuo occidental al diálogo cultural, parece pertinente que no solo la sociología de la literatura, sino la teoría, el comparatismo y la tematología literarias se hagan eco de ella. Asimismo, sería necesario que al ámbito educativo se abra a tales aportaciones: entendemos que, como expresión introductora al imaginario compartido, y responsable, en gran medida, de la futura vida lectora y social del niño, no merece menos atención.

La comunicación literaria infantil implica además la particularidad de una hermenéutica específica. Esta puede Ilevarnos hacia mecanismos interpretativos-comprensivos que ahonden en la especificidad del hecho literario infantil desde diferentes perspectivas y miradas disciplinarias. Dicha investigación, que habrá de correr a cargo de los docentes universitarios relacionados con las áreas didácticas, ha de ser trasladada al aula. En este sentido, entendemos que las especulaciones del presente artículo contraen una deuda aplicativa, que responda a una permanente retroalimentación entre teoría, praxis y metateoría sociodidáctica y literaria.

\section{Referencias bibliográficas}

Azerêdo R. T. (2003). Comprender y enseñar. Por una docencia de la mejor calidad. Barcelona: Graó.

Ballesteros, C., Llobera, M., Cambra, M., Palou, J., Riera, M., Civera, I. y Perera, J. (2001). El pensamiento del profesor. Enseñanza de la lengua y reforma. En A. Camps (coord.), El aula como espacio de investigación y reflexión (pp. 195-205). Barcelona: Graó. 
Beuchot, M. (2000). Tratado de hermenéutica analógica: hacia un nuevo modelo de interpretación. Ciudad de México: Universidad Autónoma Metropolitana.

Beuchot, M. (2004). Hermenéutica, analogía y símbolo. Barcelona: Herder.

Beuchot, M. (2008). Perfiles esenciales de la hermenéutica. Ciudad de México: Fondo de Cultura Económica.

Borda, M. (2002). Literatura infantil y juvenil. Teoría y didáctica. Granada: Grupo Editorial Universitario.

Borg, S. (2009). Introducing Language Teacher Cognition. Recuperado de http://www.education.leeds. ac.uk/assets/files/staff/borg/Introducing-language-teacher-cognition.pdf.

Bortolussi, M. (1987). Análisis teórico del cuento infantil. Barcelona: Alhambra.

Bourriaud, N. (2009). Radicante. Buenos Aires: Adriana Hidalgo Editora.

Camps, A. (2001). El aula como espacio de investigación y reflexión. Barcelona: Graó.

Carandell, J. M. (1977). Reflexiones acerca de la literatura infantil. Cuadernos de Pedagogía, 36, 19-23.

Francisco Carrera, F. J. (2016). Hermenéutica analógica, poética del haiku y didáctica de la creatividad. Una propuesta para desarrollar la interpretación, la comprensión y la creatividad literaria en el aula de lengua inglesa en Educación primaria (Tesis doctoral). Universidad de Salamanca, Salamanca, España.

Cerrillo, P. y García Padrino, J. (coords.). (1999). Literatura infantil y su didáctica. Cuenca: Universidad de Castilla-La Mancha.

Cerrillo, P. y García, P. J. (coords.). (2000). Presente y futuro de la literatura infantil. Cuenca: Universidad de Castilla-La Mancha.

Cerrillo, P.; Larrañaga, E. y Yubero, S. (2002). Libros, lectores y mediadores. La formación de los hábitos lectores como proceso de aprendizaje. Cuenca: Universidad de Castilla-La Mancha.

Cerrillo, P. y Sánchez, C. (2006). Literatura con mayúsculas. Ocnos, 2, 7-21.

Cervera, J. (1984). La literatura infantil en la educación básica. Madrid: Cincel.
Cervera, J. (1989). En torno a la literatura infantil. Revista de Filología y su Didáctica, 12, 157-168.

Cervera, J. (1992). Teoría de la literatura infantil. Bilbao: Ediciones Mensajero; Universidad de Deusto.

Chicharro, A. (2005). El corazón periférico (sobre el estudio de literatura y sociedad). Granada: Universidad de Granada.

Colom C., A. (1992). El saber de la teoría de la educación. Su ubicación conceptual. Teoría de la Educación, 4, 11-19.

Colomer, T. (2010). Introducción a la literatura infantil y juvenil actual. Madrid: Síntesis.

Croce, B. (1985). Breviario de estética. Cuatro lecciones seguidas de dos ensayos y un apéndice. Madrid: Espasa-Calpe.

Culler, J. (2000). Breve introducción a la teoría literaria. Madrid: Planeta.

D'Amore, B.; Font, V. y Godino, J. D. (2007). La dimensión metadidáctica en los procesos de enseñanza y aprendizaje de la matemática. Paradigma, 28(2), 49-77.

Del Amo, J. M. (2003). Literatura infantil: claves para la formación de la competencia literaria. Archidona: Aljibe.

Escarpit, R. (1971). Sociología de la literatura. Barcelona: Oikos-Tau.

Flick, U. (2004). Introducción a la investigación cualitativa. Madrid: Morata.

Lerer S. (2009). La magia de los libros infantiles: de las fábulas de Esopo a las aventuras de Harry Potter. Barcelona: Ares y Mares.

López T. R. (1990). Introducción a la literatura infantil. Murcia: Universidad de Murcia.

Llovet, J; Caner, R; Catelli N; Martí M. A. y Viñas P. D. (2012). Teoría literaria y literatura comparada. Barcelona: Ariel.

Lluch, G. (2003). Análisis de narrativas infantiles y juveniles. Cuenca: Universidad de Castilla-La Mancha.

Mendoza, A. (1999). Función de la literatura infantil y juvenil en la formación de la competencia literaria. En P. Cerrillo y J. García Padino (coords.), Literatura infantil y su didáctica (pp. 11-53). Cuenca: Universidad de Castilla-La Mancha. 
Merlo, J. C. (1976). La literatura infantil y su problemática. Buenos Aires: El Ateneo.

Morales Lomas, F. y Morales Pérez, L. (2011). Sociología de la literatura infantil y juvenil. Ámbitos de la creación literaria y la didáctica. Granada: Zumaya.

Morin, E. (1998). Introducción al pensamiento complejo. Barcelona: Gedisa.

Morin, E. (2004). Epistemología de la complejidad. Gazeta de Antropología, 20, s. p. Recuperado de http://www.ugr.es/ pwlac/G20_02Edgar_Morin. html

Munita, F. (2007). Creencias y saberes de futuros maestros (lectores y no lectores) en torno a la educación literaria. Ocnos, 9, 68-97.

Nicolescu, B. (2002). Manifesto of Transdisciplinarity. Nueva york: SUNY Press

Núñez, D. M. P. (2009). Literatura infantil: aproximación al concepto, a sus límites ya sus posibilidades. Enunciación, 14(1), 7-21.

Puig, E. J. S. y Salabarría R. M. C. (2013). Una aproximación a la metadidáctica como epistemología de segundo orden. Revista Dilemas Contemporáneos: Educación, Política y Valores, 1(1), s. p. Recuperado de http://files.dilemascontemporaneoseducacionpoliticayvalores.com/200000053-afae8b0a6f/ Una\%20aproximaci\%C3\%B3n\%20a\%20la\%20 Metadid\%C3\%A1ctica\%20como\%20epistemolog\%C3\%ADa\%20de\%202do\%20orden.pdf

Rico, L. (1986). Castillos en el aire. Madrid: Alhambra.

Rodríguez, C. M. P. y Colom, C. A. (1996). Teoría de la educación y ciencias de la educación: carácter y ubicación. Teoría de la Educación, 8, 43-54.
Sánchez Corral, L. (1992). (Im)posibilidad de la literatura infantil: hacia una caracterización estética del discurso. Cauce, 14-15, 525-560.

Sánchez, C. L. (1995). Literatura infantil y lenguaje literario. Barcelona: Paidós.

Sánchez, C. L. (1999). Discurso literario y comunicación infantil. En P. Cerrillo y J. García P. (eds.), Literatura infantil y su didáctica (vol. 53, pp. 89-116). Cuenca: Universidad de Castilla-La Mancha.

San Juan Álvarez, M. (2011). De la experiencia de la lectura a la educación literaria. Análisis de los componentes emocionales de la lectura literaria en la infancia y adolescencia. Ocnos, 7, 85-100.

Silva Díaz, M. C. (2001). La formación de los maestros en literatura infantil: un estudio diagnóstico. Cuatrogatos: Revista de Literatura Infantil, 5/6, s.p. Recuperado de http://www.cuatrogatos.org/archivoarticulos.html

Suárez O. M. (2005). El grupo de discusión. Una herramienta para la investigación cualitativa. Barcelona: Laertes.

Tabernero, R. (2005). Nuevas y viejas formas de contar. El discurso narrativo infantil en los umbrales del siglo XXI. Zaragoza: Prensas universitarias de Zaragoza.

Verdulla, A. (1998). Literatura infantil. Introducción en su problemática, su historia y su didáctica. Cádiz: Universidad de Cádiz.

Zipes, J. (2014). El irresistible cuento de hadas. Historia cultural y social de un género. Buenos Aires: Fondo de Cultura Económica. 